Short Communication

\title{
Simulated roots and host feeding enhance infection of subterranean insects by the entomopathogenic nematode Steinernema carpocapsae
}

\author{
D.E. Ennis *, A.B. Dillon, C.T. Griffin \\ Department of Biology, National University of Ireland Maynooth, Maynooth, Co. Kildare, Ireland
}

\section{A R T I C L E I N F O}

\section{Article history:}

Received 22 July 2009

Accepted 17 November 2009

Available online 22 November 2009

\section{Keywords:}

Steinernema carpocapsae

Hylobius abietis

Entomopathogenic nematodes

Foraging strategy

Host-finding

Vibrations

Roots

Subterranean

Insect feeding

\begin{abstract}
A B S T R A C T
Steinernema carpocapsae can be effective against root-feeding insects despite its reputation as a sedentary ambusher. In pot experiments, using twigs as surrogate roots and pine weevil larvae as targets, we tested the hypothesis that roots serve as physical routeways and conduits of feeding-associated stimuli, thus enhancing the success of $S$. carpocapsae applied at the surface against subterranean hosts. Insect mortality was lowest (25\%) in the absence of plant material, increased to $48 \%$ when twigs linked nematodes and insects, and further increased to $69 \%$ when the insects were allowed feed on the twigs. This is the first experimental support for the root-routeway hypothesis.
\end{abstract}

(c) 2009 Elsevier Inc. All rights reserved.

\section{Introduction}

Infective juveniles (IJs) of the entomopathogenic nematodes (EPN) Steinernema and Heterorhabditis seek out, enter and kill insects, usually in soil. The behavioural strategies employed by EPN species have been classified as being along a continuum from sedentary ambushers to more active cruising strategists (Campbell and Gaugler, 1997). Steinernema carpocapsae is classed as an ambush strategist, for which volatiles are unimportant in host-finding at a distance (Grewal et al., 1994; Lewis et al., 1995); most IJs remain near the soil surface (Georgis and Poinar, 1983) where they lift their body into the air in order to attach to a passing host (Campbell and Gaugler, 1993). Ambush strategists are considered to be more successful at infecting mobile, surface dwelling hosts; while cruisers are expected to infect less mobile hosts underground (Gaugler et al., 1997). Nevertheless, S. carpocapsae may sometimes perform better than its described foraging strategy might predict in parasitising subterranean root-dwelling insects, such as Capnodis tenebrionis in apricot tree roots (Martinez de Altube et al., 2008) or Hylobius abietis (pine weevil) in stumps of felled conifer trees (Dillon et al., 2006). In the pine weevil field trials, nematodes applied at soil level around tree stumps parasitised weevils feeding under the bark of tree roots up to $50 \mathrm{~cm}$ below the soil surface. While rather few S. carpocapsae IJs

\footnotetext{
* Corresponding author.

E-mail addresses: darraghennis@gmail.com (D.E. Ennis), christine.griffin @nuim.ie (C.T. Griffin).
}

penetrate deep into soil (Georgis and Poinar, 1983), on an agar substrate ambush foragers like $S$. carpocapsae exhibit ranging search (Lewis et al., 1993). We hypothesise that roots of trees or other plants may provide a physical routeway, encouraging penetration by ambush foragers deep into soil.

It is well established that plant roots affect the dispersal and host-finding of EPN both by drawing distant nematodes into the root zone, where hosts are likely to be located, and by effects on host-finding within the root zone. Roots alone are attractive (Bird and Bird, 1986; Kanagy and Kaya, 1996; Hui and Webster, 2000), and even more so when they are wounded or fed on by insects (Wang and Gaugler, 1998; Boff et al., 2001; van Tol et al., 2001; Rasmann and Turlings, 2008). The presence of roots in soil enhanced the rate of infection by EPN of non-feeding trap insects (wax moths), but only at low root density (Choo and Kaya, 1991), while high density of roots interfered with host-finding (Choo et al., 1989). Similar effects were reported by Cutler and Webster (2003). The main emphasis in all of these studies has been on the effects of volatiles, and most have employed EPN species with cruise foraging strategy which are expected to respond more strongly to such stimuli (Lewis et al., 1995). Little attention has been paid to the possibilities offered by roots as paths through soil (as proposed by Van Tol et al., 1998) and/or as conduits for transmitting vibrations from root-feeding insects to nematodes at the soil surface. Vibrations attract entomopathogenic nematodes (Torr et al., 2004) and those caused by feeding insects could potentially increase the likelihood of infection. 
The objective of this study was to assess the contribution of physical routeways with or without stimuli from feeding insects (pine weevil larvae) on infection of the larvae by S. carpocapsae.

\section{Materials and methods}

S. carpocapsae (All strain) were cultured in Galleria mellonella larvae. IJs were stored at $9{ }^{\circ} \mathrm{C}$ at a concentration of $2000 \mathrm{IJs} / \mathrm{ml}$ and were used within 3-5 weeks of harvest. Late instar $H$. abietis larvae were collected from the field and stored individually in wells of multiwell plates at $9{ }^{\circ} \mathrm{C}$ for up to 2 weeks. The lids of the plates were lined with damp tissue paper. Twigs of Sitka spruce (Picea sitchensis) used in the experiments had been removed from trees less than $24 \mathrm{~h}$ before use.

Cylindrical plastic pots (diameter $100 \mathrm{~mm}$ and height $120 \mathrm{~mm}$ ) were filled to a depth of $80 \mathrm{~mm}$ with either sand (heat-sterilised and moistened with $8 \%$ water by weight) or a $1: 1 \mathrm{v} / \mathrm{v}$ mix of this sand with milled moss peat compost $H$. abietis larvae were placed in cylindrical cages ( $15 \mathrm{~mm}$ diameter) of aluminium mesh, which could be closed at each end. Four caged insects were placed equidistant along the bottom circumference of the pot. Each substrate (sand or sand/peat mix) was used for each of four routeways/feeding treatments. These consisted of:

(1) Routeway + Feeding: surrogate conifer roots provided by twigs of $60 \mathrm{~mm}$ in length (diameter approx. $8 \mathrm{~mm}$ ) were placed in the substrate pointing from the centre diagonally down to each insect. The end of the twig was placed alongside the insect inside the cage in such a way that the insect could feed on it.

(2) Routeway Only: as (1) above except the twig was placed outside the cage of each insect.

(3) Feeding Only: a $3 \mathrm{~mm}$-long section of twig was placed in the cage with each insect.

(4) No Routeway or Feeding (=Control): a $3 \mathrm{~mm}$ section of conifer twig was placed outside the cage of each insect.

A suspension of $5000 \mathrm{IJs}$ of $S$. carpocapsae in $1 \mathrm{ml}$ water was applied to the surface of the substrate, in a $5 \mathrm{~mm}$ diameter. depression made in the centre of the surface adjacent to the tops of the twigs. Pots were covered with lids and incubated for $12 \mathrm{~h}$ at $20^{\circ} \mathrm{C}$. Insects were removed and washed with water to remove adhering IJs. The insects were placed in wells of 24-well multiwell plates and incubated at $20^{\circ} \mathrm{C}$ for up to 2 weeks. Insects that died were dissected within 3 days and the number of invading nematodes recorded.

The experiment was run three times with 20 insects for each treatment in each experiment. There was also a no-nematode control of ten insects with the Control treatment. A different batch of nematodes was used for each experiment.

Two-way analysis of variance was performed to investigate the effect of substrate and treatment. Where overall significance $(P<0.05)$ was detected, means were separated using Tukey's post hoc test, $\alpha=0.05$. Data were checked for normality using the Anderson-Darling method and, when not normal, the number of nematodes per insect were normalised using the $\log (x+1)$ transformation. Statistical analysis was carried out using Minitab 14 (Minitab Inc.).

\section{Results}

Some weevils were killed by nematodes in each treatment. Routeways/feeding treatment $(F=12.07, d f=3,16, P<0.001)$ but not substrate $(F=0.05, d f=1,16, P=0.823)$ affected the percentage of $H$. abietis larvae killed by $S$. carpocapsae, and there was no interaction between the two factors $(F=0.17, d f=3,16$,
$P=0.912$ ), therefore substrate data were combined to explore differences between the routeways/feeding treatments (Fig. 1A). The highest weevil mortality $(69.2+4.6 \%$ of insects killed by nematodes) occurred where twigs were present and the weevils were allowed to feed on them (Routeway + Feeding); this differed significantly from all other treatments, and was nearly three times higher than in the Control treatment where there was neither a routeway nor feeding $(25.0+6.1 \%)$. Where just one of these options was available (Routeway Only or Feeding Only), mortality was intermediate $(48.3+4.9$ and $35.0+4.3 \%$, respectively). Routeway Only, but not Feeding Only, differed significantly from the Control treatment. None of the insects in the no-nematode control died.

Data for numbers of nematodes penetrating $H$. abietis showed similar trends to the mortality data: routeways/feeding treatment $(F=4.63, d f=3,16, P=0.016)$ but not substrate $(F=1.80, d f=1,16$, $P=0.198$ ) affected the number of $S$. carpocapsae found in $H$. abietis larvae, and there was no interaction between the two factors $(F=0.18, d f=3,16, P=0.908)$. Combining the data for both substrates, the highest mean number of invading nematodes was found when a routeway was present and the insects were allowed to feed on it (4.16 + $0.56 \mathrm{IJs}$; Fig. 1B). This value was 10 times higher than the result in the Control $(0.43+0.14)$ from which it differed significantly. Routeway Only and Feeding Only did not differ from the Control.

\section{Discussion}

Presence of plant material as a "routeway", with or without insect feeding, resulted in significantly higher weevil mortality compared to the Control treatment, where there was neither a routeway nor feeding. It has been reported that on an agar sub-
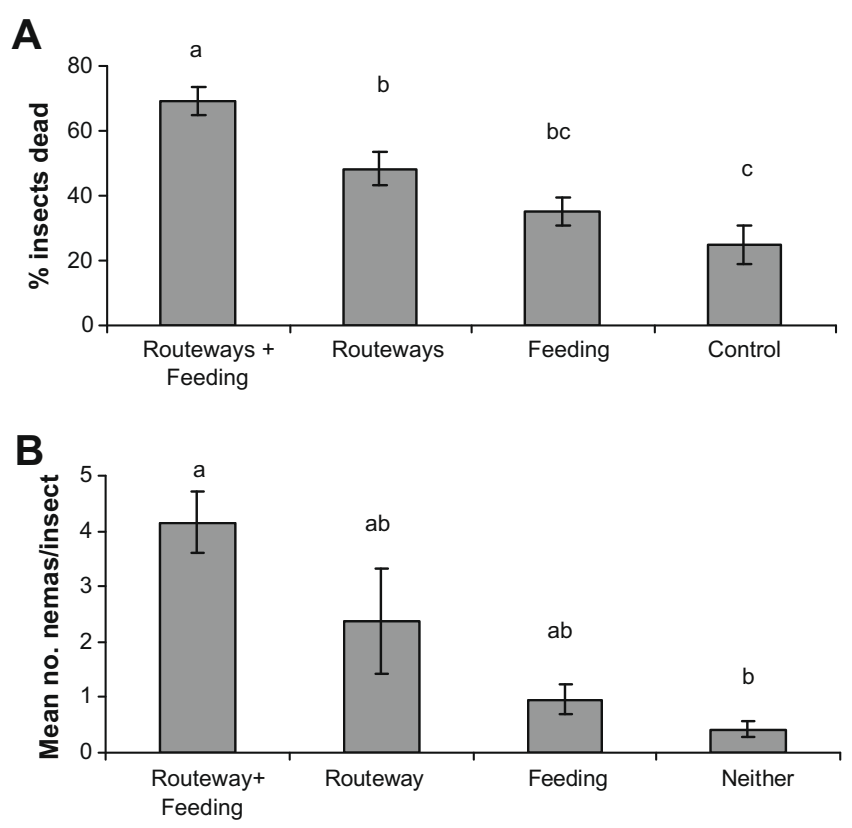

Fig. 1. (A): Mean $( \pm S E)$ mortality of pine weevil (Hylobius abietis) larvae, and (B): Mean $( \pm \mathrm{SE})$ number of Steinernema carpocapsae found upon dissection of the larvae. Weevils were exposed to $S$. carpocapsae infective juveniles in sand or a sand/peat mixture for $12 \mathrm{~h}$ at $20^{\circ} \mathrm{C}$. Route + Food $=$ Larvae were adjacent to a conifer twig that they could feed on. Route only = Larvae were adjacent to a conifer twig that they could not feed on. Food Only = Larvae were adjacent to a small piece of conifer twig that they could feed on. Control = Larvae were adjacent to a small piece of conifer twig that they could not feed on. Data shown are a mean of three experiments with 20 insects for each treatment in each experiment. Bars accompanied by the same letter are not significantly different (Tukey's test, $\alpha=0.05$ ). 
strate ambush foragers like $S$. carpocapsae exhibit ranging search (Lewis et al., 1993); tree roots or the twig used as a routeway here may provide a surface that would encourage ranging in the IJs. Soil composition and texture strongly influence EPN dispersal and infectivity (Georgis and Poinar, 1983; Koppenhöfer and Fuzy, 2006), so the fact that the medium (sand or sand/peat mix) had no effect on nematode success supports the assumption that IJs are mainly moving along the twig rather than through the medium. Moving through soil in search of cryptic hosts is presumably costly in terms of energy and time, therefore a targeted search along a root would seem to be an efficient searching mechanism for EPN seeking out root-feeding insects.

Insect mortality was higher when the twigs used as routeways were being fed on by weevil larvae than when the weevil larvae were prevented from feeding. Insect feeding may result both in release of volatiles and the propagation of vibrations. For cruise foragers such as heterorhabditids, attraction to roots on which insects are feeding may be largely due to allelochemicals released from the damaged plant, but $S$. carpocapsae is reported to respond poorly to distant volatile signals while searching (Lewis et al., 1995); moreover, the high organic content of the peat/sand mixture would reduce the transfer of chemical signals (Clarke et al., 2008; Torr et al., 2004). Torr et al. (2004) showed that artificially-produced vibrations transmitted through peat were attractive to EPN including S. carpocapsae, and since acoustic stimuli produced by insects can be transmitted for up to $30 \mathrm{~cm}$ through soil (Mankin et al., 2008) they are potentially an important source of information for EPN.

An additional effect of allowing insects to feed is that they may ingest more nematodes than non-feeding insects (Wang and Gaugler, 1998). This may have contributed to the increased mortality in insects that were allowed to feed on twigs in the substrate, but when the insects were allowed to feed on only small pieces of wood the proportion of insects killed was not significantly different to the Control treatment, suggesting that enhanced ingestion is not a major factor in this experiment.

In the absence of either feeding or twigs in the substrate, within $12 \mathrm{~h} 25 \%$ of the weevil larvae were found and infected by $S$. carpocapsae applied at least $6 \mathrm{~cm}$ away, indicating that a proportion of the IJs actively search through a sand or sand-peat substrate even in the absence of routeways. This is in accordance with previous work which shows that while the majority of $S$. carpocapsae remain in the upper zone of soil, a small proportion may migrate several centimetres into it (Georgis and Poinar, 1983).

Our findings provide support for the hypothesis that roots enhance host-finding in entomopathogenic nematodes by providing a physical routeway, especially when fed on by insects. These results provide a plausible explanation for the success of the ambush species S. carpocapsae against certain root-feeding insects (Jansson et al., 1993; Dillon et al., 2006; Martinez de Altube et al., 2008), despite its reputation for remaining at the soil surface and not responding directionally to volatiles. It should be noted, however, that "cruise" species such as Heterorhabditis are usually superior against root feeders (Van Tol and Raupp, 2005; Dillon et al., 2006). While previous studies have shown that EPN are attracted to plant roots, both damaged and undamaged, this is the first to demonstrate the importance of root-routeways in delivering EPN to subterranean hosts. It is likely that physical routeways are less important for species with cruise searching strategies, but this needs to be evaluated.

\section{Acknowledgments}

The work was financially supported by the European Regional Development Fund (INTERREG IIIA) administered through the
Welsh European Funding Office, and by the Irish National Development Plan through COFORD, the National Council for Forest Research and Development (ABATE project).

\section{Appendix A. Supplementary material}

Supplementary data associated with this article can be found, in the online version, at doi:10.1016/j.jip.2009.11.004.

\section{References}

Bird, A.F., Bird, J., 1986. Observations on the use of insect parasitic nematodes as a means of biological control of root-knot nematodes. Journal of Parasitology 16 , 511-516.

Boff, M.I.C., Zoon, F.C., Smits, P.H., 2001. Orientation of Heterorhabditis megidis to insect hosts and plant roots in a Y-tube sand olfactometer. Entomologia Experimentalis et Applicata 98, 329-337.

Campbell, J.F., Gaugler, R., 1993. Nictation behaviour and its ecological implications in the host search strategies of entomopathogenic nematodes (Heterorhabditidae and Steinernematidae). Behaviour 126, 155-169.

Campbell, J.F., Gaugler, R., 1997. Inter-specific variation in entomopathogenic nematode foraging strategy: dichotomy or variation along a continuum? Fundamental and Applied Nematology 20, 393-398.

Choo, H.Y., Kaya, H.K., Burlando, T.M., Gaugler, R., 1989. Entomopathogenic nematodes - host-finding ability in the presence of plant-roots. Environmental Entomology 18, 1136-1140.

Choo, H.Y., Kaya, H.K., 1991. Influence of soil texture and presence of roots on host finding by Heterorhabditis bacteriophora. Journal of Invertebrate Pathology 58, 279-280.

Clarke, K., Hill, G.A., Pugsley, T., 2008. Improved VOC bioremediation using a fluidized bed peat bioreactor. Process Safety and Environmental Protection 86 283-290.

Cutler, C.G., Webster, J.M., 2003. Host-finding ability of three entomopathogenic nematode isolates in the presence of plant roots. Nematology 5, 601-608.

Dillon, A.B., Ward, D., Downes, M.J., Griffin, C.T., 2006. Suppression of the large pine weevil Hylobius abietis (L.) (Coleoptera: Curculionidae) in pine stumps by entomopathogenic nematodes with different foraging strategies. Biological Control 38, 217-226.

Gaugler, R., Lewis, E., Stuart, R.J., 1997. Ecology in the service of biological control: the case of entomopathogenic nematodes. Oecologia 109, 483-489.

Georgis, R., Poinar, G.O., 1983. Effect of soil texture on the distribution and infectivity of Neoaplectana carpocapsae (Nematoda, Steinernematidae). Journal of Nematology 15, 308-311.

Grewal, P.S., Lewis, E.E., Gaugler, R., Campbell, J.F., 1994. Host finding behaviour as a predictor of foraging strategy in entomopathogenic nematodes. Parasitology $108,207-215$

Hui, E. Webster, J.M., 2000. Influence of insect larvae and seedling roots on the host-finding ability of Steinernema feltiae (Nematoda: Steinernematidae). Journal of Invertebrate Pathology 75, 152-162.

Jansson, R.K., LeCrone, S.H., Gaugler, R., 1993. Field efficacy and persistence of entomopathogenic nematodes (Rhabditida: Steinernematidae, Heterorhabditidae) for control of sweetpotato weevil (Coleoptera: Apionidae) in Southern Florida. Journal of Economic Entomology 86, 1055-1063.

Kanagy, J.M.N., Kaya, H.K., 1996. The possible role of marigold roots and alpha terthienyl in mediating host-finding by steinernematid nematodes. Nematologica 42, 220-231.

Koppenhöfer, A.M., Fuzy, E.M., 2006. Effect of soil type on infectivity and persistence of the entomopathogenic nematodes Steinernema scarabaei, Steinernema glaseri, Heterorhabditis zealandica, and Heterorhabditis bacteriophora. Journal of Invertebrate Pathology 92, 11-22.

Lewis, E.E., Gaugler, R., Harrison, R., 1993. Response of cruiser and ambusher entomopathogenic nematodes (Steinernematidae) to host volatile cues. Canadian Journal of Zoology-Revue Canadienne De Zoologie 71, 765-769.

Lewis, E.E., Grewal, P.S., Gaugler, R., 1995. Hierarchical order of host cues in parasite foraging strategies. Parasitology 119, 207-213.

Mankin, R.W. Brandhorst-Hubbard, J., Flanders, K.L, Zhang M. Crocker, R.L. Lapointe, S.L., Martinez de Altube, M.d.M., Strauch, O., Fernandez de Castro, G., Martinez Pena, A., 2008. Control of the flat-headed root borer Capnodis tenebrionis (Linne) (Coleoptera: Buprestidae) with the entomopathogenic nematode Steinernema carpocapsae (Weiser) (Nematoda: Steinernematidae) in a chitosan formulation in apricot orchards. BioControl (Dordrecht) 53 , 531-539.

Martinez de Altube, M.d.M., Strauch, O., Fernandez de Castro, G., Martinez Pena, A., 2008. Control of the flat-headed root borer Capnodis tenebrionis (Linne) (Coleoptera : Buprestidae) with the entomopathogenic nematode Steinernema carpocapsae (Weiser) (Nematoda : Steinernematidae) in a chitosan formulation in apricot orchards. BioControl 53, 531-539.

Rasmann, S., Turlings, T.C.J., 2008. First insights into specificity of belowground tritrophic interactions. Oikos 117, 362-369.

Torr, P., Heritage, S., Wilson, M.J., 2004. Vibrations as a novel signal for host location by parasitic nematodes. International Journal for Parasitology 34 997-999. 
Van Tol, R.W.H.M., Van Bezooijen, J., Ketelaars, T.A.C.M., 1998. Searching behaviour of entomopathogenic nematodes: roots and soil temperature determine success of black vine weevil (Otiorhynchus sulcatus) control. IOBC/WPRS Bulletin Insect Pathogens and Insect Parasitic Nematodes 21 (4), 187-191.

Van Tol, R.W.H.M., Raupp, M.J., 2005. Nursery and tree application. In: Grewal, P.S., Ehlers, R.-U., Shapiro-Ilan, D.I. (Eds.), Nematodes as Biological Control Agents. CABI Publishing. pp. 167-190.
Van Tol, R.W.H.M., van der Sommen, A.T.C., Boff, M.I.C., van Bezooijen, J., Sabelis, M.W., Smits, P.H., 2001. Plants protect their roots by alerting the enemies of grubs. Ecology Letters 4, 292-294.

Wang, Y., Gaugler, R., 1998. Host and penetration site location by entomopathogenic nematodes against Japanese beetle larvae. Journal of Invertebrate Pathology 72, 313-318. 